\title{
Measurement of Tourist Satisfaction Based on Destination Attributes Using Kano Model in Tourist Destination: A Case of Borobudur Temple
}

\author{
Deacta Ayu Digpasari ${ }^{1}$, Herry Irawan ${ }^{2}$, Astri Ghina ${ }^{3}$ \\ \{deactaayu@student.telkomuniversity.ac.id ${ }^{1}$, \\ herryir@telkomuniversity.ac.id ${ }^{2}$, aghnia@telkomuniversity.ac.id $\left.{ }^{3}\right\}$ \\ School of Economic and Business Telkom University, Bandung, Indonesia ${ }^{1,2,3}$
}

\begin{abstract}
Tourism has become a leading sector in Indonesia. However, developing tourist destination still becomes a problem, especially to maximize tourist satisfaction. To develop the tourist destination is necessary to evaluate the performance of competitive destination's attributes to provide high-quality tourism, thus will maximize tourist satisfaction. The research aims to measure tourist satisfaction based on its non-linear effect of destination attributes from user-generated content to provide credible information. Penalty-Reward Contrast Analysis and Kano Model were used to analyze the performance of destination attributes and measure tourist satisfaction. The research found that customized service and quality of shopping were destination attributes with the excitementlow performance will not affect tourist satisfaction. Furthermore, destination management with the performance category and low performing, as the determining factor of the rate of tourist satisfaction. The research is to function as an evaluation for taking an integrative approach as a reference for the development of tourist destinations.
\end{abstract}

Keywords: Destination Attributes, Kano Model, Tourist Satisfaction, User Generated Content.

\section{Introduction}

The world tourism sector is a key driver in developing a country. It shows sustainable growth in 2019, marked by the increase in the worldwide number of tourists globally, showing by $38 \%$ or 1.5 billion international tourist arrivals [27]. The Indonesian tourism sector is declared as the leading sector to stimulate economic growth in tourism development and improve people's welfare through its multiplier effect. The Indonesian tourism sector is also experiencing an increase in the world's Tourism Competitiveness Index rating of 2019, capable of occupying 40 from 140 countries [30]. On the other hand, from 2017 to 2019, foreign tourist arrivals didn't achieve the set targets and experienced a decline 
in targets. Therefore, the government seeks to develop the tourism sector by declaring super-priority tourist destinations. One of them is the Borobudur Temple, a splendor of the Buddhist monument, and it was designated as a UNESCO World Heritage in 1991. However, there are critical obstacles encountered by a tourist destination, and one of those is the lack of service quality development. So, it's necessary to improve performance on destination attributes. Also, collaborations among tourism stakeholders such as government and tourism destination management are required to strengthen each tourism sector policy [15].

The destination attribute essentially refers to the attraction factor and positive or negative characteristics based on tourist destination performance [7][19]. Improvements to the priority of destination attributes are required as a reference in establishing a tourist destination capacity and the best business strategies to provide high-quality tourism and create a competitive advantage in the tourist destination. Moreover, destination attributes are intended to stimulate tourist satisfaction from the visiting experience [24]. Tourist satisfaction is assumed to be one of the primary instruments in the economy drive in the market sector and affects tourist arrivals and total income [4]. Identification of tourist satisfaction can be seen from comparing the fulfillment of tourist expectations and actual perceptions of the destination attributes performance. The comparison creates a perception conclusion leading to satisfaction or dissatisfaction with the tourist destination. However, tourist satisfaction has a non-linear effect on destination attributes performance. For instance, there are destination attributes with high performance, but they don't increase tourist satisfaction. Otherwise, there are destination attributes with low performance, but they don't create tourist dissatisfaction. Therefore, this study used two approaches. Penalty-Reward Contrast Analysis was used to analyze the performance of tourist destination attributes. Then, the results will be integrated with the Kano Model to measure tourist satisfaction based on destination attributes. Next, Asymmetric Impact Performance Analysis (AIPA) is used as a visualization technique from destination attributes' priority on tourist satisfaction based on resource allocation.

Tourist satisfaction can be affected by the availability of information in various mass media. It's both from the Internet and mass media, as well as recommendations from the closest and trusted people [23]. The presence of the Internet in the tourism sector builds opportunities in the emergence of various platforms as a meeting point for tourists and information availability. TripAdvisor is the world's largest tourism travel site, and it provides a variety of information on recommended features such as destination descriptions, user ratings, and online reviews. Besides, tourists experience a behavioral 
transformation, identified by the transition from traditional activities to technology-based activities. Tourists begin to plan their travel activities using technology, such as booking accommodation and transportation tickets [17]. Moreover, tourists also publish their travel information through online review sites or their social media, also called user-generated content. Through usergenerated content, tourists can perceive other tourists' visiting experience and the actual condition of a destination to support their decision-making before visiting the tourist destination. For tourism stakeholders, the utilization of usergenerated content can be used to stimulate strategic information as a stimulus to increase competitive advantage and excellence of tourism competitiveness. It's because user-generated content is a valuable source of information and innovative ideas, which is in the form of satisfaction and honest review by tourists during a visit to a tourist destination.

Many of the newest research measure tourist satisfaction based on destination attributes within tourism scope [21][25]. Subsequently, there is limited research measuring tourist satisfaction having non-linear effects on the destination attributes performance [3]. However, as time goes by, research has not fully utilized the data of user-generated content to measure tourist satisfaction based on destination attributes. Thus, this research aims at a) analyzing the destination attributes performance based on the data of usergenerated content b) measuring tourist satisfaction based on non-linear effects of destination attribute performance c) identifying a priority of destination attributes based on resource allocation. This research's findings serve as an evaluation in adopting a more holistic and integrative approach as a reference for the tourist destinations' development.

\section{Literature Review}

\subsection{Tourist Destination in the Tourism Sector}

The tourism sector is a unique industry that involves various activities, cultures, facilities, and individuals. It has developed into a significant industry for the economy of a community, region, and country. Moreover, the tourism sector becomes one of the industries that tend to be sensitive to either bad or good economic conditions and can rapidly recover from bad economic conditions or other environmental effects [9]. In Indonesia, tourism establishment managed by optimizing tourist destination establishment as a dynamic concept represents a group of main products from tourist destination that collectively offer experiences for the visitors [13]. A tourist destination 
refers to a place whose location is far from the visitors' home and comprises a group of destination tours or mobile destinations [20]. Besides, tourist destination has actual border such as geography, politic, or border created by the market [19].

\subsection{The relation of Tourist Satisfaction and Destination Attributes}

The type of tourist destination capacity is addressed to meet tourists' necessity by observing the destination attributes [13]. Destination attributes are assumed as a factor attracting tourists to visit a destination [19]. The importance of destination attributes explanation was strengthened by a previous study [21]. Destination attributes monitoring is a measurement of tourist experience and can stimulate behavior to go traveling to a destination. Further, it also increases the opportunity of tourism establishment. Destination attributes refer to attraction factors and positive or negative characteristics based on a destination performance [7][19]. Several previous research types explained that destination attributes' contribution can significantly affect the quality of tourist experience and adequately stimulate tourist satisfaction [11]. Besides, it becomes an effective strategy in tourist decision making [16][25]. In this research, destination attributes shown in Figure 1.

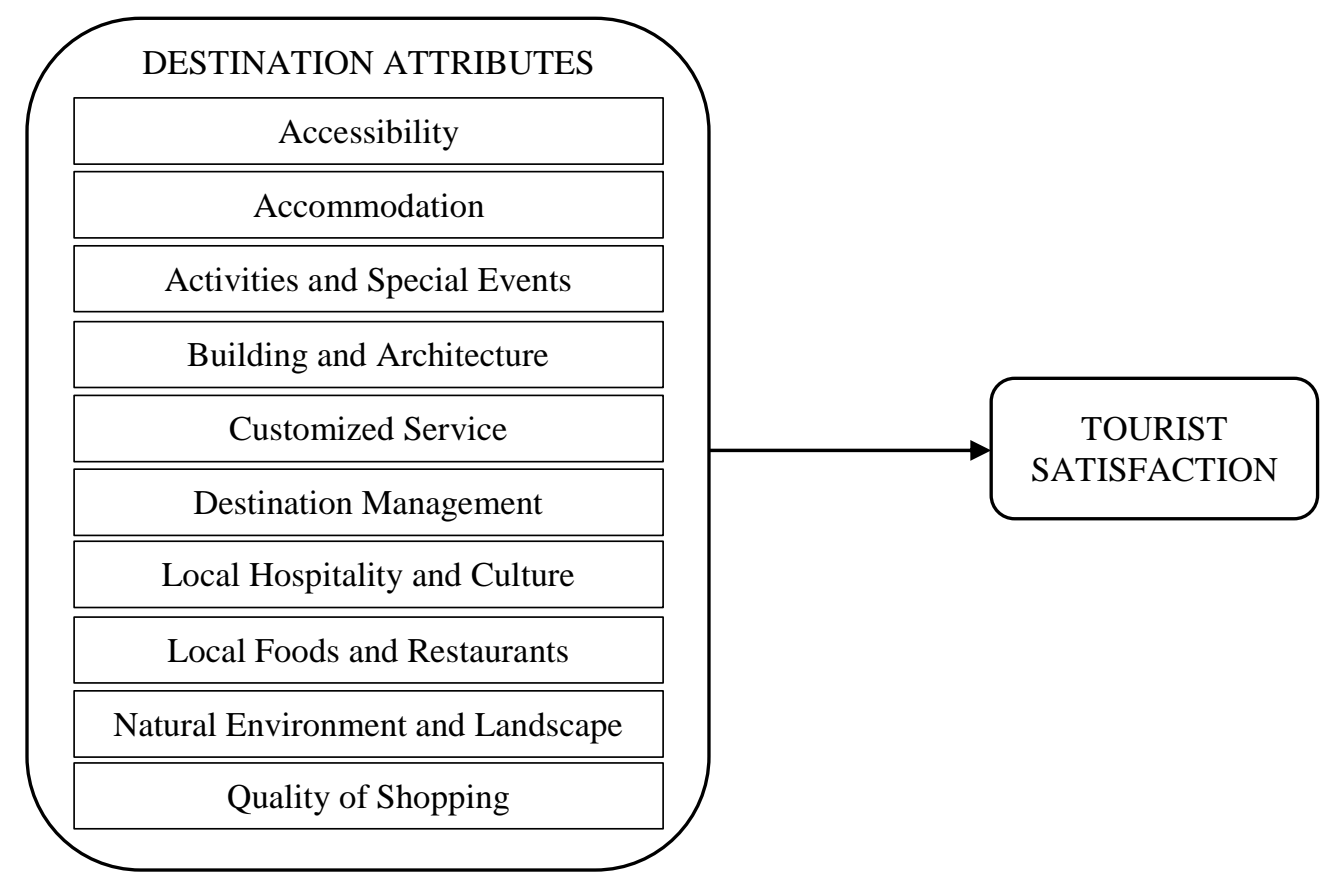

Fig. 1. The Research Framework 
Generally, tourist satisfaction is defined as tourist feeling perceived from comparing a product or service performance and tourist expectation [18]. These comparisons lead to tourist satisfaction and dissatisfaction with a product or service. Commonly, satisfaction is a measure of destination attributes performance that meets tourist demand. Meanwhile, dissatisfaction occurs if destination attributes performance doesn't meet tourist demand [23]. Tourist satisfaction supports creating good relations that cause the emergence of talks and positive word of mouth on the public's tourist destination. Besides, there will be potential tourist loyalty enacted in their revisit act, thus can enhance its competitive position than the competitor. On the contrary, dissatisfaction leads to responses and negative word of mouth that could rapidly spread to the public. Besides, it can damage its image and abandon tourist attraction to visit the tourist destination.

\subsection{Kano Model}

As time goes by, previous studies claim that tourist satisfaction and dissatisfaction have a non-linear effect on destination attributes performance [3][5]. It means that destination attributes have low performance without creating tourist dissatisfaction and destination attributes with high performance but don't significantly create tourist satisfaction. Tourist satisfaction measuring with non-linear effect on destination attributes measured by using the Kano Model is the process of service attributes identification as a measure of service performance in fulfilling tourist expectations [29]. Through the Kano Model, there obtained destination attributes results that defined into three categories, such as basic, performance, and excitement. Basic is the basic attributes category that becomes a minimum requirement identified by certain services customers [25]. Basic is part of non-linear that if destination attributes performance is high and meets customers' demand, so it doesn't enhance consumer dissatisfaction. On the other hand, if destination attributes performance is low and doesn't meet consumer expectations, it will heavily influence tourist dissatisfaction [5]. Performance represents the linear attributes category between tourist satisfaction and tourist destination attributes. In other words, if destination attributes have high performance and meet tourist demand or exceed tourist expectations, so they can enhance tourist satisfaction. However, when destination attributes are low, so there will be tourist dissatisfaction [5]. Excitement can be defined as the required attributes category or consumer value increase and is defined as non-linear. So, it can be concluded that dissatisfaction increase happens if destination attributes performance is 
high. Yet, if destination attribute performance is low, it doesn't cause tourist dissatisfaction [25].

\subsection{User-Generated Content}

User-generated content is a valuable information data source or as new information media assumed as feedback, honest review, perception from consumer experience provided widely, freely, and accessible wherever and whenever [14]. User-generated content can be defined as a benchmark of tourist satisfaction and decision making [1]. Several previous types of research used online reviews as user-generated content containing valuable information of tourist experience that has an important aspect, review, as a useful information description [1][5][10][26][31]. Moreover, previous research explains other significant aspects, rating, as a depiction of a short evaluation assessment of the whole tourist experience. Therefore, it eases the readers to quickly identify the writer's behavior and sentiment [12].

\section{Methodology}

Based on the above literature review, we developed a research workflow of this study as shown in Figure 2.

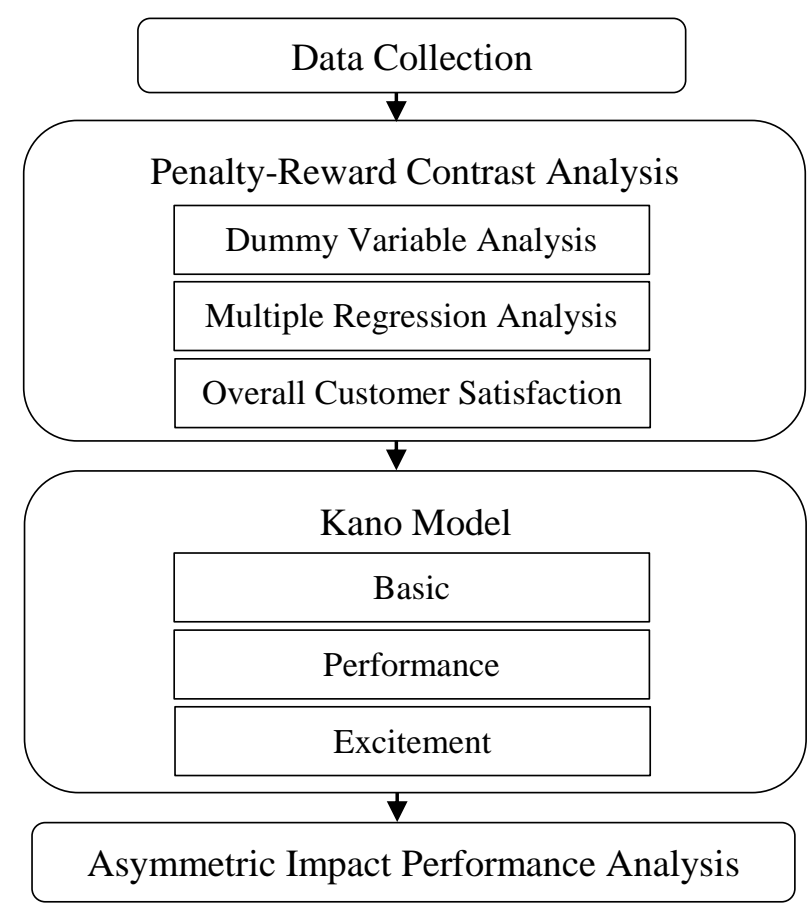

Fig. 2. The Research Workflow 


\section{Data Collection}

This study collected data from the TripAdvisor website as the world's largest tourism platform with the keyword "Borobudur Temple". Data collection was done by scrapping using Web Harvy. The collected data is user-generated content from online reviews and ratings provided by tourists for three years from 2016-2019 and obtained 7,545 reviews. The online review contains comments about their experience of visiting the Borobudur Temple. The online review data will be classified into destination attributes consisting of accessibility, accommodation, activities and special events, building and architecture, customized services, destination management, local hospitality and culture, local foods and restaurants, natural environment and landscape, and quality of shopping. Those destination attributes were adopted from the previous research [1][11][21]. The online reviews excluded from the destination attribute will be removed to obtain relevant data and generate the cleaning data of 4,230 reviews. Furthermore, the rating given by tourists is used as a brief evaluation rating of overall tourist satisfaction consisting of 5-scales Likert in which $1=$ "terrible", 2 = "poor", 3 = "average", 4 = "very good", and 5 = "excellent".

\section{Penalty-Reward Contrast Analysis}

Measuring tourist satisfaction based on destination attributes is done by two approaches Penalty-Reward Contrast Analysis (PRCA) and Kano Model. PRCA is defined as a general approach to explore destination attributes' performance on tourist satisfaction having non-linear effects into different categories [5]. PRCA aims at identifying destination attributes of low and high performance. If the destination attribute has high performance as a "reward" and if the performance is low as a "penalty" [2]. In this research, the stages of PRCA is carried out using dummy variables and multiple regression analysis. It's to calculate the values of reward and penalty and overall customer satisfaction based on ratings. Previous research described rating as a source of information with high credibility to measure non-linear effects of tourist satisfaction based on destination attributes [3][5][12][14].

Before conducting multiple regression analysis, the first step in this research is the analysis of 2 dummy variables, which are $d_{l p}^{i}$ and $d_{h p}^{i}$ from the rating of destination attribute. The following provisions in analyzing dummy variables [5]:

a. $d_{l p}^{i}$ is "a penalty" aimed at analyzing destination attributes with low performance, calculated based on the lowest rating in each destination attribute. If the rating is ' 1 ', it's given a value of 1 . Meanwhile, if the rating is '2,3,4 or 5', it's given a value of 0 . 
b. $\quad d_{h p}^{i}$ is "a reward" aimed at analyzing destination attributes with high performance, the measurement is based on the highest rating in each destination attribute. If it's rated '5', it's given a value of 1 , while if it's rated '1,2,3 or 4', it's given a value of 0 .

Furthermore, multiple linear regression analysis is performed as a data analysis technique used to identify variables' relationships and explore interesting data factors [8]. Multiple regression analysis can also analyze more than one independent variable, however, it's limited to one dependent variable. Previous research used multiple regression as a statistical technique to measure tourist satisfaction with non-linear effects on the destination attributes performance [3][5]. Some previous research used unstandardized coefficients to determine coefficients [5]. On the other hand, previous research uses standardized coefficients to determine coefficients [3][6]. In this research, standardized coefficients were used to get the reward coefficient as Reward Indices (RI) and penalty as Penalty Indices (PI).

Next step, we calculated the value of destination attribute performance. The calculation is performed by calculating the destination attribute's average rating [5][22]. After that, the calculation process on overall customer satisfaction is performed at Borobudur Temple, see equation (1). If the value of destination attribute performance is above the overall customer satisfaction value, it's categorized as High Performance. However, if it's below the overall customer satisfaction value, it's categorized as Low Performance [5].

$$
\mathrm{OCS}=\beta_{0}+\sum_{\mathrm{i}=1}^{\mathrm{n}}\left(\beta_{l p}^{i} d_{l p}^{i}+\beta_{h p}^{i} d_{h p}^{i}\right)+\varepsilon
$$

\section{Kano Model}

After obtaining the PRCA results, we performed the Kano Model is defined as a theory of identification of primary factors in service attributes to measure satisfaction and minimum requirements desired by customers [31]. Kano model consists of three categories, namely basic, performance, and excitement. Previous researches [3][5] identified destination attributes in the Kano Model category by calculating the Impact Asymmetric Index.

The Impact Asymmetric (IA) Index is intended to measure the extent to which destination attributes generate tourist satisfaction with non-linear effects, see equation (2) [3][5]. IA Index has vulnerable values from -1 to +1 . 


$$
\mathrm{IA}_{i}=\frac{\left|\beta_{h p}^{i}\right|-\left|\beta_{l p}^{i}\right|}{\left|\beta_{l p}^{i}\right|+\left|\beta_{h p}^{i}\right|}
$$

Then, we identify the Kano Model category for each destination attribute based on the IA index value, provided that the IA value of the destination attribute is as follows [3][5]:

- $1 \leq \mathrm{IA}_{i} \leq-0.1$, it's categorized as basic.

- $-0.1 \leq \mathrm{IA}_{i} \leq 0,1$, it's categorized as performance.

- $0.1 \leq \mathrm{IA}_{i} \leq 1$, it's categorized as excitement.

Asymmetric Impact Performance Analysis

Asymmetric Impact Performance Analysis (AIPA) was first proposed by previous research, and it's a simple visual technique by describing attributes into a graph to identify the priority of the attributes to increase overall customer satisfaction [6]. It's presented with the order of priority of the destination attributes from the most critical to not too critical as follows: Basic - Low Performance $\rightarrow$ Performance - Low Performance $\rightarrow$ Excitement - Low Performance $\rightarrow$ Basic - High Performance $\rightarrow$ Performance - High Performance $\rightarrow$ Excitement - High Performance.

Furthermore, AIPA involves two metrics, IA Index and attributes performance. In AIPA, the $\mathrm{X}$ coordinate is the destination attribute performance, and the Y coordinate is the IA Index. AIPA is divided into two parts: low performance and high performance based on the average of destination attributes' overall performance. Moreover, AIPA is also divided into three parts based on two parallel lines, with the following conditions:

- -0.1 and +0.1 are the IA Index axis points

- Between -1 and -0.1 is the basic category borderline

- Between -0.1 and +0.1 is the performance category borderline

- Between +0.1 and +1 is the excitement category borderline

\section{Results and Discussions}

Based on the multiple regression analysis calculations using SPSS software, the regression coefficients were obtained from each destination attribute. The regression coefficient is a penalty and reward coefficient that will be used to calculate overall customer satisfaction. Penalty aims to analyze the low performance of destination attributes, so that negative values indicate it. 
Meanwhile, reward aims to analyze the high performance of destination attributes to obtain positive results.

Besides, the calculation of multiple regression analysis shows the model, and the overall coefficient was significant $(F=14595.194, p=0.000)$. Based on Table 1 , the value of $\mathrm{R}^{2}$ is 0.873 . It can be concluded that the destination's overall attributes influence tourist satisfaction by $87.3 \%$. Others are influenced by other factors that were not examined in this study.

Table 1. The Regression Analysis Result of Borobudur Temple

\begin{tabular}{lcc}
\hline \multirow{2}{*}{ Destination Attributes } & \multicolumn{2}{c}{ Regression Coefficient } \\
\cline { 2 - 3 } & $\beta_{h p}^{i}$ & $\beta_{l p}^{i}$ \\
\hline Accessibility & 0.776 & -0.398 \\
Accommodation & 0.700 & -0.474 \\
Activities and Special Events & 0.902 & -0.199 \\
Building and Architecture & 0.794 & -0.390 \\
Customized Service & 0.691 & -0.469 \\
Destination Management & 0.582 & -0.590 \\
Local Hospitality and Culture & 0.866 & -0.256 \\
Local Foods and Restaurants & 0.788 & -0.336 \\
Natural Environment and Landscape & 0.859 & -0.274 \\
Quality of Shopping & 0.702 & -0.466 \\
$\mathrm{R}^{2}$ & \multicolumn{2}{c}{0.873} \\
$\mathrm{~F}$ & \multicolumn{2}{c}{14595.194} \\
\hline
\end{tabular}

Note: $\mathrm{p}<0.01$

Next, we analyzed the destination attributes performance using a PenaltyReward-Contrast Analysis approach. An in-depth understanding of destination attributes performance based on tourist preferences can be one of the best competitive strategies to provide high-quality tourism and create a competitive advantage in the tourist destination. Determination of destination attributes performance refers to the value of performance and overall customer satisfaction. If the performance value is higher than overall customer satisfaction, it belongs to high performance. Conversely, if the performance value is lower than overall customer satisfaction, it's included in the low performance category. Table 2 shows overall customer satisfaction value is 4,566 and the results in destination attributes are dominated by high performance and activities and special events as destination attribute with the highest performance values. Conversely, there are destination attributes that have low performance including customized service, quality of shopping, and 
destination management as destination attributes with the lowest performance value.

Table 2. The Result of The Performance Category of Borobudur Temple

\begin{tabular}{lccc}
\hline \multicolumn{1}{c}{ Destination Attributes } & Performance & OCS & $\begin{array}{c}\text { Performance } \\
\text { Category }\end{array}$ \\
\hline Accessibility & 4.611 & & High \\
Accommodation & 4.746 & & High \\
Activities and Special Events & 4.753 & & High \\
Building and Architecture & 4.639 & & High \\
Customized Service & 4.421 & \multirow{2}{*}{4.566} & Low \\
Destination Management & 4.092 & & Low \\
Local Hospitality and Culture & 4.723 & & High \\
Local Foods and Restaurants & 4.690 & High \\
Natural Environment and Landscape & 4.733 & High \\
Quality of Shopping & 4.247 & Low \\
\hline
\end{tabular}

Note: OCS: Overall Customer Satisfaction

After that, we analyzed the destination attribute performance using the Kano Model. At this stage, we identified destination attributes and divided them into categories of the Kano Model consisting of basic, excitement, and high performance. It aims to know the extent of destination attributes' contribution in increasing the satisfaction of tourists visiting Borobudur Temple. Thus, tourism stakeholders can evaluate and improve the performance of destination attributes according to their respective contributions.

Based on Table 3, destination attributes are dominated by the excitement category and activities and special events have the highest IA value of 0.72 . This excitement category is an added value for tourists, so that the destination attributes included in this category have great potential in increasing and achieving a high level of satisfaction. Also, tourism stakeholders can be focused on improving destination attributes' performance in the excitement category. It can improve competency and long-term service quality services in the business [31]. Besides, one destination attribute is included in the performance category, namely destination management with the lowest IA score of 0.079 . This performance category contributes equally to the satisfaction and dissatisfaction of tourists. 
Table 3. The Kano Model Result of Borobudur Temple

\begin{tabular}{lcc}
\hline \multicolumn{1}{c}{ Destination Attributes } & IA Index & Kano Model \\
\hline Accessibility & 0.437 & Excitement \\
Accommodation & 0.297 & Excitement \\
Activities and Special Events & 0.721 & Excitement \\
Building and Architecture & 0.465 & Excitement \\
Customized Service & 0.287 & Excitement \\
Destination Management & 0.079 & Performance \\
Local Hospitality and Culture & 0.638 & Excitement \\
Local Foods and Restaurants & 0.589 & Excitement \\
Natural Environment and Landscape & 0.617 & Excitement \\
Quality of Shopping & 0.303 & Excitement \\
\hline
\end{tabular}

From the tourism sector, tourist satisfaction can be measured by identifying the destination attributes performance. A comparison between the performance of destination attributes and tourist expectations can be concluded as a reference to measure tourist satisfaction and dissatisfaction with a tourist destination. Making satisfaction can affect the revisit increase, tourist loyalty, and spread positive information that is effective for marketing purposes. However, if it causes dissatisfaction among tourists, it will affect the level of tourist visits, investment, and cause a decline in the tourist destination image. Thus, measuring tourist satisfaction based on destination attribute becomes important as a strategy for developing the tourism sector. Table 4 shows that the average performance of destination attributes was able to create tourist satisfaction. Destination attributes that generate tourist satisfaction are attributes included in the category of excitement-high performance and excitement-low performance. Excitement-high performance is a category that creates very high tourist satisfaction due to the high performance of destination attributes.

Besides, there are two destination attributes included in the category of excitement-low performance, such as customized service and quality of shopping. This category has a low performance based on performance value, but it doesn't make tourists dissatisfied. This category proves that tourist satisfaction is non-linear in the performance of destination attributes. Customized service is a destination attribute that focuses on the services provided for tourists. Based on the data, it was found that foreign tourists cost higher than domestic tourists. This gap leads to a problem, although a high entrance ticket is comparable to the services offered due to the availability of professional tour guide services. However, several tour guides have low 
English-speaking proficiency in serving information. Quality of shopping is a destination attribute related to shopping services. At Borobudur Temple, there's a large tourist market that offers a variety of local products. However, the large tourist markets and sellers inconvenience tourists to visit sacred destination and cause negative impact on the religious performance since there are some sellers tend to force tourists to buy their products.

At last, there is one destination attribute that makes tourist dissatisfaction, namely destination management included in the performance category. This category has a low performance on the destination attribute. This shows the inability of tourism stakeholders to meet the expectations of tourists. Therefore, additional resource allocation is needed to improve destination attributes' performance in making a competitive advantage of a tourist destination. Destination management is a destination attribute regarding security, order, cleanliness, and smooth traffic in a tourist destination. Based on the data, it was found that Borobudur Temple has a high number of tourist visits, especially on weekends and holidays. This is proven by the long queue on the stairs to reach the top level at Borobudur Temple. This certainly has the potential to reduce the quality of the tourist experience since tourists visiting Borobudur Temple are eager to enjoy its sacred and religious atmosphere. However, heavy traffic makes them less comfortable while visiting.

Table 4. Tourist Satisfaction Based on Destination Attributes

\begin{tabular}{lcc}
\hline \multicolumn{1}{c}{ Destination Attributes } & \multicolumn{1}{c}{$\begin{array}{c}\text { Destination Attributes } \\
\text { Performance }\end{array}$} & $\begin{array}{c}\text { Tourist } \\
\text { Satisfaction }\end{array}$ \\
\hline Accessibility & Excitement - High Performance & Satisfaction \\
Accommodation & Excitement - High Performance & Satisfaction \\
Activities and Special Events & Excitement - High Performance & Satisfaction \\
Building and Architecture & Excitement - High Performance & Satisfaction \\
Customized Service & Excitement - Low Performance & Satisfaction \\
Destination Management & Performance - Low Performance & Dissatisfaction \\
Local Hospitality and Culture & Excitement - High Performance & Satisfaction \\
Local Foods and Restaurants & Excitement - High Performance & Satisfaction \\
Natural Environment and Landscape & Excitement - High Performance & Satisfaction \\
Quality of Shopping & Excitement - Low Performance & Satisfaction \\
\hline
\end{tabular}

In addition to analyzing the destination attributes performance, measurement of tourist satisfaction based on destination attributes can also be done by providing recommendations of strategic priorities sequence based on destination attributes. That priority sequence is based on the most critical to not 
too critical level within the allocation of resources as a reference in the improvement and development of crucial factors of destination attributes. Previous research explained that destination attributes with low performance are the main priority in the focus of improvement to increase tourist satisfaction [3][5]. Figure 3 describes the priority sequence of destination attributes based on resource allocation. It's known that destination management is the first priority order since the attribute defines tourists' dissatisfaction in Borobudur temple. The next priority is quality of shopping and customized service as destination attributes in excitement-low performance category. In this destination attribute, the focus of improvement needs to be achieved a high level of tourist satisfaction and improved to be superior among competitors in the tourism sector. Then, the priority order of other destination attributes in an order are accessibility, building and architecture, local foods and restaurants, local hospitality and culture, natural environment and landscape, accommodation, and events and special events. These destination attributes are included in the category of excitement-high performance. These destination attributes' performance needs to be maintained as a determinant of tourist satisfaction and significant tourist destination strength.

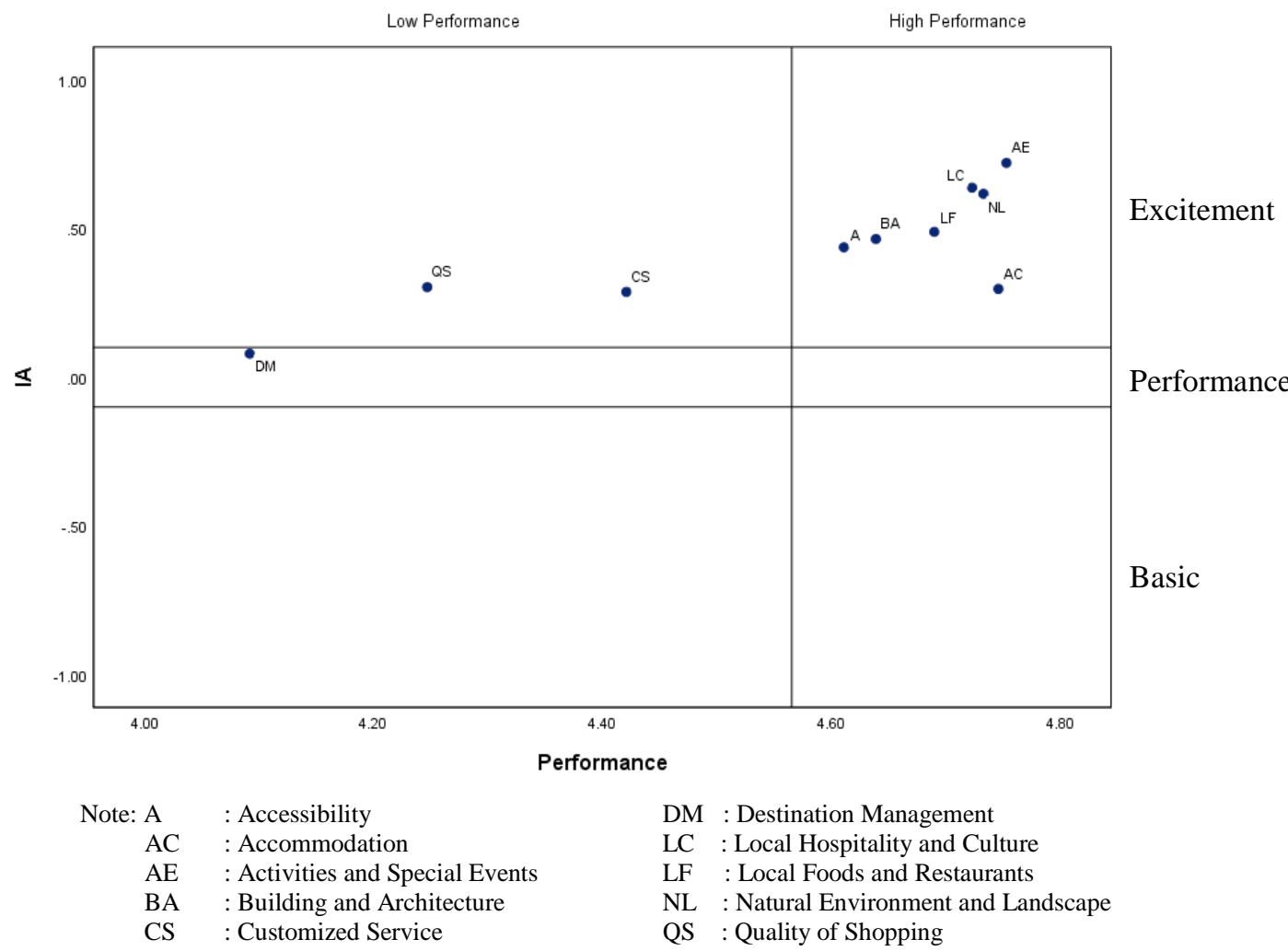

Fig. 3. The AIPA Plot of Borobudur Temple 


\section{Conclusion}

This study obtained new insights in measuring tourist satisfaction based on destination attributes by using the Kano Model at Borobudur Temple. First, it's necessary to utilize information from user-generated content on the TripAdvisor site in the form of online reviews and ratings as a form of evaluation of tourist perceptions. The information obtained contributes to analyzing the characteristics of a tourist destination, which is represented by destination attribute in this study. User-generated content also has information credibility and is assumed to be an honest review that represents tourist satisfaction during a visit to a tourist destination to encourage tourist decision making before visiting a tourist destination. Based on tourists' latest behavior, the information searches were conducted through the reviews written by other tourists before visiting. Therefore, this study has a practical implication for the tourism sector. It's crucial for tourism stakeholders to monitor user-generated content from tourists as the first information gate or alarm call to control and improve the destination attribute performance, mainly the customized service, destination management, and quality of shopping. Accordingly, it can develop a tourist destination image and increase the number of tourist visits.

The second finding in this study is using the Penalty-Reward Contrast Analysis method and the Kano Model as an associated approach that contributes to measuring non-linear tourist satisfaction on destination attributes. This associated approach can also potentially differentiate destination attributes according to its performance and contribution to tourist satisfaction. Also, few studies use user-generated content, namely online reviews that are processed and analyzed by using these two approaches in the tourism sector, mainly tourist destination [3][5]. This becomes a reference for this research to fill the gap.

By using these two approaches, it's confirmed that tourist satisfaction has a non-linear effect on the performance of destination attributes. This is proven by the destination attributes of customized service and quality of shopping included in the excitement category, but both have low performance. This attribute doesn't contribute to making tourist dissatisfaction. However, it's necessary to improve destination attributes as a strengthening step to increase tourist satisfaction. Based on the findings on customized services, the government and tourism destination management are encouraged to organize professional training programs for staff and tour and travel agents to increase their knowledge regarding tourist destination. It also aims to develop communication skills and foreign languages application, mainly English as the world's universal language. Hence, improving the quality of human resources, productivity, and the economy is the future expectation. Tourism destination management can 
also provide tour packages integrated with tourist destinations in the surrounding area to provide reasonable offers at affordable prices.

Based on the findings on the quality of shopping, the practical implication required to be executed by the government is to collaborate between business actors and suppliers around Borobudur Temple to provide more varied and highquality products. The government also needs to cooperate with tourism destination management to organize training programs for business actors to develop communication skills in offering products to tourists professionally. Meanwhile, tourism destination management can manage the tourist market with modest and narrow distance to make it more comfortable for tourists to visit.

Furthermore, the third finding in this study is that destination management is a destination attribute included in the performance category and has low performance, that makes tourist dissatisfaction at Borobudur Temple and becomes the priority in allocating resources to improve destination attributes. This is a crucial factor for the government to immediately make improvements to destination management regarding security, order, cleanliness, and smooth traffic in a tourist destination. The government and tourism destination management should increase some security staff's placement to hold emergency calls and set visit mobility scenarios to control order on high demand tourist traffic. Thus, it provides a more comfortable travel experience for tourists.

Moreover, this research could be a reference for an effective strategy to develop tourist destinations that refer to the 3As, including attraction, accessibility, and amenities. The development of a tourist destination is also a form of growth in the tourism sector to increase tourist visits. Thus, specific outputs are given to tourism stakeholders from the destination attributes performance and priority improvements to destination attributes on tourist satisfaction and the foundation strength for development competitiveness at a later stage through innovation and the quality of human resources improvement.

This study has several limitations. This study only uses the rating of the destination attributes as a benchmark for measuring tourist satisfaction. Therefore for further research, it's expected that there is a combination of ratings and other variables, including a word weight and a forum group discussion conducted with various parties from tourism stakeholders. Besides, future researches can also analyze from different platforms and conduct studies in a lengthy period. Hence, providing thorough insight is expected. 


\section{References}

[1] Ahani, A., Nilashi, M., Yadegaridehkordi, E., Sanzogni, L., Tarik, A. R., Knox, K., Ibrahim, O. Revealing Customers' Satisfaction and Preferences Through Online Review Analysis: The Case of Canary Islands Hotels. Retailing and Consumer Services. 2019:331343.

[2] Albayrak, T. Importance Performance Competitor Analysis (IPCA): A Study of Hospitality Companies. International Journal of Hospitality Management. 2018.

[3] Albayrak, T., \& Caber, M. Destination attribute effects on rock climbing tourist satisfaction: An Asymmetric Impact-Performance Analysis. Tourism Geographies. 2016.

[4] Atabeb, H. A. Customer Satisfaction in Tourism Industry. International Journal of Scientific and Research Publications. 2019. 9(1).

[5] Bi, J.-W., Liu, Y., Fan, Z. P., \& Zhang, J. Exploring Asymmetric Effects of Attribute Performance on Customer Satisfaction in The Hotel Industry. Tourism Management. 2020.

[6] Caber, M., Albayrak, T., \& Loiacono, E. T. The Classification of Extranet Attributes in Terms of Their Asymmetric Influences on Overall User Satisfaction: An Introduction to Asymmetric Impact-Performance Analysis. Journal of Travel Research. 2013. 24(11):1288-1300.

[7] Chahal, H., \& Devi, A. Destination Attributes and Destination Image Relationship in Volatile Tourist Destination: Role of Perceived Risk. Metamorphosis. 2015. 14(2).

[8] Cohen, J., Cohen, P., West, S. G., \& Aiken, L. S. Applied Multiple Regression/Correlation Analysis for the Behavioral Sciences. 3 ed. Lawrence Erlbaum Associates, 2003.

[9] Cook, R. A., Hsu, C. H., \& Taylor, L. L. Tourism the Business of Hospitality and Travel. 6 ed. New York: Pearson, 2018.

[10] Díaz, M. R., \& Rodríguez, T. F. A Methodology for a Comparative Analysis of The Lodging Offer of Tourism Destinations Based on Online Customer Reviews. Destination Marketing \& Management. 2017.

[11] Eom, T., Han, H., \& Song, H. Discovering the Perceived Attributes of CBT Destination Travelers in South Korea: A Mixed Method Approach. Tourism Management. 2020.

[12] Fang, B., Ye, Q., Kucukusta, D., \& Law, R. Analysis of the perceived value of online tourism reviews: Influence of readability and reviewer characteristics. Tourism Management. 2016:498-506.

[13] Fletcher, J., Fyall, A., Gilbert, D., \& Wanhill, S. Tourism Principles and Practice. 6 ed. United Kingdom: Pearson, 2018.

[14] Guo, Y., Barnes, S. J., \& Jia, Q. Mining Meaning from Online Ratings and Reviews: Tourist Satisfaction Analysis using Latent Dirichlet Allocation. Tourism Management. 2017:467-483.

[15] Irawan, H., Digpasari, D.A., \& Alamsyah, A. Social Network Analysis of The Information Dissemination Patterns and Stakeholders' Roles at Superpriority Tourism Destinations in Indonesia. In: Noviaristanti, S., Hanafi, H.M., \& Trihanondo, D. Understanding Digital Industry. Conference on Managing Digital Industry Technology and Entrepreneurship 2019 (CoMDITE 2019); 10-11 July 2019. Bandung. Taylor \& Francis Group: CRC Press/Balkema; 2020. 285-288.

[16] Jo, D., Park, H. Y., Choe, Y., \& Kim, D. K. Destination-Selection Attributes for International Association Meetings: A Mixed-Methods Study. Destination Marketing \& Management. 2019:61-72. 
[17] Kim, K., Park, O. J., Yun, S., \& Yun, H. What Makes Tourists Feel Negatively About Tourism Destinations? Application of Hybrid Text Mining Methodology to Smart Destination Management. Technological Forecasting \& Social Change. 2017.

[18] Kotler, P., \& Armstrong, G. Principles of Marketing. 17 ed. Pearson, 2018.

[19] Kotler, P., Bowen, J. T., Makens, J. C., \& Baloglu, S. Marketing for Hospitality and Tourism. 7 ed. Pearson, 2017.

[20] Lohmann, G., \& Netto, A. P. Tourism Theory Concepts, Models, And Systems. CABI, 2017.

[21] Moon, H., \& Han, H. Destination attributes influencing Chinese travelers' perceptions of experience quality and intentions for island tourism: A case of Jeju Island. Tourism Management Perspectives. 2018:71-82.

[22] Mustafa, H., Omar, B., \& Mukhiar, S. N. Measuring Destination Competitiveness: An Importance-Performance Analysis (IPA) of Six Top Island Destinations in South East Asia. Asia Pacific Journal of Tourism Research. 2019. 25(3):223-243.

[23] Oliver, R. L. Satisfaction A Behavioral Perspective on The Consumer. 2 ed. Taylor \& Francis, 2010.

[24] Semrad, K. J., \& Rivera, M. A Destination Performance Analysis through the Comparison of Tourists and Stakeholders' Perceptions: The Case of Curaçao. Tourism \& Hospitality. 2015. 4(4).

[25] Thuy, V. T., \& Thao, H. D. Ecotourists' satisfaction and dissatisfaction: asymmetric effects of service attributes. Journal of Asian Business and Economic Studies. 2019. 26(2):189205.

[26] Tontini, G., Bento, G. D., Milbratz, T. C., Volles, B. K., \& Ferrari, D. The Critical Incident Technique (CIT) and Penalty-Reward Contrast Analysis (PRCA) applied to online reviews on TripAdvisor: Evaluation of satisfaction of Hotel Customers. International Journal of Hospitality Management. 2017:106-116.

[27] UNWTO World Tourism Organization. World Tourism Barometer. 2020.

[28] Velikova, N., Slevitch, L., \& Soulek, K. M. Application of Kano Model to Identification of Wine Festival Satisfaction Drivers. International Journal of Contemporary Hospitality Management. 2016.

[29] Wijaya, T. Manajemen Kualitas Jasa: Desain Servqual, QFD, dan Kano Disertai Contoh Aplikasi dalam Kasus Penelitian. West Jakarta: Indeks, 2019.

[30] Word Economic Forum. Travel and Tourism Competitiveness Report 2019. 2019.

[31] Zhang, Y., \& Cole, S. T. Dimensions of lodging guest satisfaction among guests with mobility challenges: A mixed-method analysis of web-based texts. Tourism Management. 2016:13-27. 